\title{
Bivariate Association Between Malaria Prevalence and Risk Factors
}

\author{
Garba Sahabi Adamu *, Gerald Onwuka ** \\ * Department of Mathematics, Waziri Umaru Federal Polytechnic, Birnin Kebbi, Nigeria \\ ** Department of Mathematics and Statistics, Kebbi State University of Science and Technology Aliero, Kebbi State Nigeria \\ DOI: 10.29322/IJSRP.11.11.2021.p11916 \\ http://dx.doi.org/10.29322/IJSRP.11.11.2021.p11916
}

\begin{abstract}
This study was carried out to assess the malaria prevalence and risk factors in children aged $6-59$ months. The data used for the analysis was obtained from the 2018 Nigeria standard demographic and health survey (NDHS). The sample was obtained through a stratified two-stage cluster sampling. The sample consists of 10609 children aged $6-59$ months. Members of the sample were tested for malaria parasite through rapid diagnostic test (RDT). Fourteen malaria risk factors were identified and subjected to screening Philips et al., (2009), Kanyangarara et al., (2016). The screening involves testing for multicollinearity and linearity in order to satisfy assumptions for binary logistic regression model. Three factors failed the test and eleven were included as independent covariates in the binary logistic regression analysis. Dichotomous response variable of the results of RDT was the dependent variable. Analysis was carried out in IBM SPSS version 20.0. The results showed overall malaria prevalence through RDT was $38.6 \%$. North West region had the highest malaria prevalence $(11.9 \%)$ in relation to other regions. South South had the least prevalence of $3.1 \%$. Nine of the eleven malaria risk factors were significantly associated with malaria prevalence. The odds of malaria positivity increased in North West region as well as for lower wealth index, males, lower level of education, age and number of children. Similarly, odds of malaria positivity decreases in children sleeping under bed nets, SS genotype, household with higher wealth index and increased maternal level of education.
\end{abstract}

\section{BACKGROUND}

$M^{\prime}$ alaria is among the most public health challenge across the globe and Africa in particular. Nigeria was reported to have the largest incidence of malaria cases. Seventy six percent (76\%) of the population live in high transmission areas and twenty four percent (24\%) in low transmission areas USAID (2019). Nigeria contributes twenty seven percent $(27 \%)$ of global malaria burden in 2016 and accounts for twenty three percent (23\%) of the global estimated malaria deaths. In Nigeria, malaria risk spins across socio-economic arena. However, it was shown to have more impact on the less developed part of Nigeria. Malaria fact sheet (2016). Between 40 to 50 percent of malaria prevalence in children of 6 to 59 months is in the North West. The prevalence of malaria depends on multiple factors such as age, geographic and socioeconomic variables, climate, and many others. The task is to identify the relevant malaria risk factors and their respective effect on malaria prevalence in children to enables us include only the relevant covariates in the modeling and analysis of malaria risk factors of child mortality. (Samadoulougou et al., 2014, Dawaki et al., 2016 Eunice et al., 2017, Fekadu et al., 2018, Morakinyo et al., 2018, Whiteman et al., 2018, Hasyim et al., 2019, Tesfay et al., 2019).

\section{INTRODUCTION}

Many Researches have been done to examine association between malaria prevalence and the risk factors of malaria Siri (2014), Ayano and Amentie (2018). The aim of this paper is to find out the association between malaria prevalence and each of the selected risk factors. This is with a view to include only the most relevant risk factors in the analysis of the main research titled "Modeling and Analysis of Malaria Risk Factors of Child Mortality".

Malaria transmission and prevalence varies across the states and regions in Nigeria and can be said to be not uniformly distributed (Malaria Operational Plan 2019). This variation can also be found in respect of rural-urban settings, socio-economic groups, environmental or ecological diversity etc (Severe Malaria Observation 2019). Many literatures associate malaria with poverty, poor sanitary conditions, type of housing, sleeping or not sleeping inside insecticide treated bed nets, living near mosquito breeding sites, absence of malaria intervention programs, poor education and ignorance, and other life-style issues (Konradsen $e t$ al., 2003, Sintasath et al., 2005, Ayele et al., 2012, Tesfahunegn et al., 2019, Herrera et al., 2020). Therefore it is of paramount importance to identify the association of the risk factors with the prevalence of malaria.

Konradsen et al., (2003) observed that a distance of less than 750 meters between a house and the mosquito breeding site was strongly associated with the presence of Anopheles Culicifacies which is the main malaria vector in Sri Lanka. They further found poor housing construction as an independent malaria risk factor. Ajakaye and Ibukunoluwa (2020) revealed age as a significant factor for malaria. They found children in $6-10$ years age range to have higher odds for malaria infection. This is in line with the work of Kanyangarara et al., (2016). They observed that malaria was positively associated with age. They also observed age ranges less than 5, 5-14, and 15-24 years had approximately 2.7 times the odds of malaria positivity. This means individuals who were younger than 25 years have higher risk of malaria infection. They also found sleeping under a bed net decrease the odds of malaria infection. They also indicated altitude as a significant determinant 
risk factor for malaria transmission. In other words, living in higher altitude greater or equal to 850 meters above sea level reduces the odds of malaria infection compared to less than 800 meters above the sea level. Increased risk of malaria transmission was observed along the international borders and may be attributable to poor access to healthcare facilities coupled with climatic conditions that favors malaria transmission. Kanyangarara et al., (2016).

According to Philips et al., (2009), ethnicity and parasitemia were important and independent risk factors for severe falciparum malaria. Their findings revealed that black patients had a significantly reduced risk of developing WHO-defined severe falciparum malaria, whereas Asian patients had 8.05-fold odds of severe falciparum malaria higher than the black patients. They also found black patients had reduced risk of an unfavorable outcome and of prolonged stay in the hospital compared with the risk for white or Asian patients. They also observed that none of the black patients died of severe falciparum malaria in contrast to their Asian counterparts.

Malaria is known to be highly heterogeneous in nature. This means malaria infection has several etiologies. Research has shown that glucose-6-phosphate dehydrogenase deficiency in female children and use of an insecticide treated bed net was associated with lower risk of malaria. This is in addition to living in a residence distant from a swamp which is considered as the strongest predictor of malaria risk. Clark et al., (2008). Adam et al., (2005) found no association between age parity and malaria. Their findings indicated high risk of malaria for women who attended the antenatal clinic in their third trimester. Environmental risk variables, knowledge about malaria and treatment efforts were found to affect malaria transmission. This include night time habits, wearing of closed clothes, using mosquito bed nets, knowledge about malaria transmission, knowledge about malaria prevention were all associated with malaria transmission. Putri et al., (2020).

Sluydts et al., (2014) carried out a research to assess the spatial clustering and risk factors of malaria infections. Their results showed the age group $5-14$ tends to be more exposed to plasmodium spp. and falciparum malaria. They found no differences in malaria prevalence based on gender. Their results also indicated more risk of malaria infection for ethnic minorities compared to ethnic majority. Individuals with axillary temperature were observed to have high risk for plasmodium malaria infection. Further, they found no association between plasmodium spp. infections and sleeping times. However, they observed risk for malaria infection in persons that stayed overnight in their plot hut. According to this finding, overnight stay in the forest and use of bed net were not significant for any specie of plasmodium malaria. Increasing age in children, low mid-upper arm circumference and absence of several household assets were found to be independent predictors of malaria infection. Gahutu et al., (2011). Yadav et al., (2014) analyzed socio-economic determinants for malaria transmission risk. Their findings revealed a decrease in malaria with increase of monthly income. Type of housing was also found to be a significant risk factor of malaria transmission where good housing is associated with a decrease in malaria transmission. No significant association was observed between educational level and malaria occurrence. Higher occurrence of malaria was reported in participants who did not use bed net. In another research, HIV status, place of residence and wealth quartile were observed to be independently associated with malaria infection. Chaponda (2017).

Homan et al., (2016) used standard linear regression model to investigate spatially variable risk factors for malaria in a geographically heterogeneous landscape. Their findings revealed socio-economic status, outdoor occupation and population density were associated with increased malaria risk. They observed that the relationship of malaria with risk factors vary spatially over the locations. This is similar to the findings of Bah (2020) that demographic and socio-economic factors like age, wealth quartile and educational levels of parent were predictors of malaria in under five years children. Poor socio-economic conditions and poor housing conditions of the household are positively associated with malaria infection. Children and female household members are the most vulnerable to malaria risk. Ayele et al., (2012). They further revealed malaria risk was significantly associated with gender, age, source of water, toilet facility, number of rooms in the household, material used for walls and roofing. Spraying insecticide to the house was observed to be one of the means of reducing the risk of malaria infection. Ayele et al., (2012).

Xiang et al., (2018) investigated association between malaria incidence and meteorological factors. Their findings showed a relationship between temperature, average relative humidity and malaria. They observed a $1^{\circ} \mathrm{C}$ increase in maximum temperature resulted in $6.7 \%$ increase of malaria. A warm climate was considered to potentially increase the risk of malaria. It was observed that unscreened windows for households surrounded by mosquito breeding sites were independent factor associated with malaria infection. Mwalimu et al., (2020). This agrees with the findings of Abossie et al., (2020) that malaria infection is highly prevalent in children between 37 and 59 months old and proximity of residence to stagnant water and non-usage of insecticide treated nets are the most dominant risk factors of malaria infection.

Cahyaningrum and Sulistyawati (2018) found educational level, presence of cattle cage within 100 meters of the house, not sleeping under a bed net and not closing the doors and windows from 6 P.M. to 5 A.M. were significantly associated with malaria infection. In another research finding, maternal education and household wealth are each independently associated with lower malaria parasitemia in children. It was observed that extent of the relationship tends to be larger for household wealth. It was also found that risk factors of malaria are lower in urban residence compared to rural areas with approximately $40 \%$ lower risk. The finding revealed lower risk in insecticide treated net use but found no significant effect for high quality housing. Household size is associated with malaria risk increase. Siri (2014).

Ernst et al., (2009) examined environmental, sociodemographic and behavioral determinants of malaria risk. The finding showed that malaria risk was associated with low education level of female household heads, overnight travel, living near swamp water and keeping livestock near the house at night. They also observed higher malaria risk for household with a metal roof with no ceiling or separate kitchen. Their finding also showed no effect of open eaves and uncovered windows on malaria risk. The environmental risk factors observed in this finding were flat land, living close to forests, having bushes near the house but not trees. Ramdzan et al., (2020) uncovered significant associations between malaria infection and socio-demographic factors such as 
sex, occupation and geographical area. They observed higher proportion of malaria infection of males than females. Higher proportion of infection among employed people than those unemployed. Higher malaria infection was recorded in the rural areas when compared to urban centers. They found no significant association between malaria infection and age, ethnicity or nationality. Long lasting insecticide treated nets were observed not any longer sufficient protection against malaria infection even when in good condition and relatively new. Mosha et al., (2020). There was no evidence to show association between malaria infection prevalence and socio-economic status or spatial clustering. Pullan et al., (2010). Seyoum (2018) suggested a very important association between malaria and sex, age, education level and marital status. He further revealed sex, education level, age and marital status are significantly determining the prevalence of malaria.

\section{Objective of the study}

The objectives of this study are;

i. To identify malaria risk factors,

ii. $\quad$ To find out malaria prevalence in children aged 6-59 months,

iii. To assess the association between malaria prevalence and malaria risk factors.

\section{Methodology}

The Demographic and Health Survey (DHS) was established by the United States Agency for International Development (USAID) in 1984. The program covers over seventy countries and conducted multiple DHS surveys to provide useful data for decision making. The first Standard Nigerian Demographic and Health Survey (NDHS) was carried out in 1990. The second NDHS was conducted thirteen years later that is in 2003. Since then, NDHS is being conducted every five years to obtain reliable data in demographic and health in accordance with the country's health and development plans. From 1990 t0 2020 has conducted seven surveys including Malaria Indicator Surveys (MIS) in 2010 and 2015. The NDHS 2018 used in this research was the seventh and labeled NDHS VII. The survey was designed to obtain data and make it available for population and health monitoring and evaluation in Nigeria. The demographic and health survey (DHS) provides reliable data of demographic and health indicators such as family planning, nutrition, breast feeding, fertility, maternal and child health, mortality, domestic violence, HIV/AIDS, female genital mutilation, sexually transmitted disease, environmental sanitation, disability, malaria and anemia, migration and host of others.

\section{Data Source}

The data used for the analysis in this study was obtained from the 2018 Nigeria standard demographic and health survey which was the seventh conducted in Nigeria. The 2018 NDHS was carried out for a period of five months. That is, from $14^{\text {th }}$ August to $29^{\text {th }}$ December 2018. The sampling frame used was the population and housing census of the Federal Republic of Nigeria (NPHC) conducted in 2006 by the National Population commission.Nigeria was divided into states and each state is subdivided into local government areas and each local government is further subdivided into wards and these were used as administrative units. Each locality was subdivided into convenient areas called Enumeration Areas (EA). The primary sampling unit (PSU) or cluster for the 2018 NDHS was defined on the basis of EA's from the 2006 EA census frame.

\section{The Sample}

The sample for the 2018 NDHS was a stratified two-stage sample. Stratification was carried out by separating each of the 36 states and Federal Capital Territory (FCT) into urban and rural areas. 74 sampling strata were identified. Samples were selected independently in every stratum in two stage selection. Implicit stratifications were obtained at each of the lower administrative levels by sorting the sampling frame before sample selection according to administrative order and by using a probability proportional to size selection during the first stage of sampling. In the first stage, 1400 EA's were selected with probability proportional to EA size. EA size was the number of households in the EA. List of households served as sampling frame or the selection of households in the second stage. In the second stage, a fixed number of 30 households were selected in every cluster using equal probability systematic sampling. A nationally representative sample of 41821 women age $15-49$ years in 4821 households and 13311 men age 15-59 years in one-third of the sampled households were interviewed. A sample of 10609 children aged 6-59 months was collected, tested for malaria parasitemia and used for data analysis.

\section{Malaria Testing}

Malaria testing was done for children aged 6-59 months. This was obtained from a drop of blood taken from a finger prick (or heel prick for children aged 6-11 months). A drop of blood was tested immediately using the SD Bioline Ag p.f. $(\mathrm{HRP}=\mathrm{II})^{\mathrm{TM}}$ rapid diagnostic test (RDT) believed to be a qualitative test for the detection of histidine-rich protein II (HRP-II) antigen of plasmodium falciparum (pf) in human whole blood. Plasmodium falciparum is the predominant plasmodium specie in Nigeria. A tiny volume of blood is captured with a disposable sample applicator and placed in the wall of the testing device. All health technicians were trained to perform RDT on the field according to the manufacturer's instructions.

\section{Variables of Malaria Risk Factors}

Fourteen (14) variables were listed and tested for multicollinearity upon which eleven were selected for analysis. These are; Age in Months, cluster altitude, location of source of water, sleeping inside mosquito net by children, wealth index, mother's educational level, sex of the children, place of residence, region, number of children and genotypes of children.

\section{Logistic Regression}

Let $y_{i}$ be the malaria status of a child $i$. Let malaria positive be 1 and 0 otherwise. The binary response data follows a Bernoulli distribution.

$y_{i}=\operatorname{Brnoulli}\left(\pi_{i}\right)$

Where $\pi_{i}$ is the probability of a positive outcome.

Let

$W^{\prime}=\left(w_{i 1}, w_{i 2}, \ldots . w_{i p}\right)$

be a matrix of explanatory variables. The linear predictor is 
$\eta_{i}=W_{i}^{\prime} \beta_{i}$

(3)

Thus the ordinary logistic regression with appropriate link function is given by

$\eta_{i}=\log \left(\frac{\pi_{i}}{1-\pi_{i}}\right)=\beta_{0}+\beta_{i} W_{i}^{\prime}$

(4)

Where $\beta_{0}$ is intercept, $\beta_{i}$ is a vector of regression coefficients and $W_{i}^{\prime}$ is a covariate vector.

Thus the odd ratio is given by

(5)

$$
e^{\log \left(\frac{\pi_{i}}{1-\pi_{i}}\right)}=e^{\beta_{0}+\beta_{i} W_{i}^{\prime}}
$$

Hence

$$
\frac{\pi_{i}}{1-\pi_{i}}=e^{\beta_{0}+\beta_{i} W_{i}^{\prime}}
$$

(6)

Weisberg (2005)

\section{Variable Description}

Dependent variable: The response variable for this study was the malaria status of a child aged 6-59 months. The status is dichotomous as malaria positive or malaria negative measured through rapid diagnostic test (RDT). In other words, the outcome variable is binary.

\section{Independent Variables}

The explanatory variables used for this study were classified into three groups: Environmental factors; cluster altitude, region and place of residence. Biological factors such as; age, sex and genotype. Socio-economic factors include; sleeping inside insecticide treated nets, wealth index mother's educational level and number of children.

Cluster altitude (meters), number of children and age of members of the sample were considered as continuous variables. Region was categorized into six geo-political zones as North East, North West, North Central, South South, South East and South West. Place of residence is categorical (Rural/Urban), Sex (male or female), sleeping inside bed net (all, none, some and no net), wealth index (poorest, poorer, middle, richer and richest), mother's educational level (no education, primary, secondary and higher). Genotype is in six categories AA, AS, AC, SC, SS and other. Location of source of water was grouped into own dwelling, own yard and other.

\section{Results}

Binary logistic regression was carried out in IBM SPSS version 20.0 to determine the bivariate association between malaria prevalence and malaria risk factors. Table 1 gives the results of malaria rapid test for all the six geo-political zones.

\begin{tabular}{|l|l|l|}
\hline & Frequency & Percentage \\
\hline $\begin{array}{l}\text { Malaria } \\
\text { Negative }\end{array}$ & 6511 & 61.4 \\
\hline $\begin{array}{l}\text { Malaria } \\
\text { Positive }\end{array}$ & 4098 & 38.6 \\
\hline Total & 10609 & 100 \\
\hline
\end{tabular}

Thus the overall malaria prevalence according to the rapid diagnostic test is $38.6 \%$. The breakdown of the malaria prevalence showed the North West zone has the highest malaria prevalence while South East has the least (Table 2).

\begin{tabular}{|c|c|c|c|c|}
\hline \multirow[t]{2}{*}{ Zone } & \multicolumn{2}{|c|}{ Frequency } & \multicolumn{2}{|c|}{ Percentage } \\
\hline & Positive & Negative & Positive & Negative \\
\hline $\begin{array}{l}\text { North } \\
\text { Central }\end{array}$ & 750 & 1115 & 40.2 & 59.8 \\
\hline $\begin{array}{l}\text { North } \\
\text { East }\end{array}$ & 742 & 1216 & 37.9 & 62.1 \\
\hline $\begin{array}{l}\text { North } \\
\text { West } \\
\end{array}$ & 1260 & 1147 & 52.3 & 47.7 \\
\hline $\begin{array}{l}\text { South } \\
\text { East } \\
\end{array}$ & 457 & 1170 & 28.1 & 71.9 \\
\hline $\begin{array}{l}\text { South } \\
\text { South }\end{array}$ & 330 & 823 & 28.6 & 71.4 \\
\hline $\begin{array}{l}\text { South } \\
\text { West }\end{array}$ & 559 & 1040 & 35.0 & 65.0 \\
\hline Total & 4098 & 6511 & & \\
\hline
\end{tabular}

Table 2 Malaria prevalence according to zones

Binary logistic regression analysis was carried out to find the effect of gender, region, genotype, wealth index, sleeping under insecticide treated bed net, mother's education, location of source of water, place of residence, cluster altitude, age and number of children on the likelihood of being malaria positive. The overall model was statistically significant compared to the null model $\chi^{2}(28)=1641.214, p<0.05$, Nagelkerke $R^{2}=0.21$. The model predicted $67.6 \%$ of the cases correctly. Region ( $\mathrm{p}<0.001)$, Place of residence $(\mathrm{p}<0.001)$, Cluster altitude $(\mathrm{p}<0.001)$, sleeping under insecticide treated bed net $(p<0.001)$, wealth index $(p<0.001)$, mother's educational level $(p<0.001)$, age $(p<0.001)$, number of children $(\mathrm{p}<0.001)$ were statistically significant while genotype, $(\mathrm{p}=0.11)$, location of source of water $(\mathrm{p}=0.441)$ were not significant.

Table 3 gives the results of malaria risk factors analysis and association between the risk factors and malaria prevalence.

Table 1 Results of Malaria Rapid Diagnostic Test (RDT)

Table 3 Malaria Risk Factors and Associated Prevalence

\begin{tabular}{|l|l|l|l|l|}
\hline Risk Factors & Prevalence (\%) & Odd Ratio & 95\% CI & p-Value \\
\hline Region & & & & \\
North Central & 40.2 & 0.570 & $0.584-0.672$ & 0.000 \\
North East & 37.9 & 0.348 & $0.290-0.417$ & 0.000 \\
North West & 52.3 & 0.690 & $0.574-0.829$ & 0.000 \\
\hline
\end{tabular}

This publication is licensed under Creative Commons Attribution CC BY. 


\begin{tabular}{|c|c|c|c|c|}
\hline South East & 28.1 & $0.527(-)$ & $0.446-0.624$ & 0.000 \\
\hline South South & 28.6 & $0.436(-)$ & $0.360-0.527$ & 0.000 \\
\hline South West (Ref) & 35.0 & & & \\
\hline $\begin{array}{l}\text { Type of Place of } \\
\text { Residence }\end{array}$ & & & & \\
\hline Urban & 74.4 & $0.654(-)$ & $0.588-0.727$ & 0.000 \\
\hline Rural (Ref) & 46.5 & & & \\
\hline Cluster Altitude & & 1.000 & $0.999-1.000$ & 0.000 \\
\hline Below $500 \mathrm{~m}$ & 38.3 & & & \\
\hline Above $500 \mathrm{~m}$ & 40.8 & & & \\
\hline Sleeping Under Bed Net & & & & \\
\hline & & & & \\
\hline All Children & 37.5 & 1.132 & $0.985-1.302$ & 0.000 \\
\hline Some Children & 39.4 & $0.979(-)$ & $0.881-1.088$ & 0.692 \\
\hline No net (ref) & 49.3 & 1.345 & $1.148-1.574$ & 0.000 \\
\hline Wealth Index & 34.6 & & & \\
\hline Poorest & & & & \\
\hline Poorer & 56.0 & 6.554 & $5.288-8.124$ & 0.000 \\
\hline Middle & 50.3 & 5.445 & $4.441-6.677$ & 0.000 \\
\hline Richer & 38.9 & 3.747 & $3.097-4.534$ & 0.000 \\
\hline Richest (Ref) & 28.4 & 2.600 & $2.157-3.134$ & 0.000 \\
\hline Sex & 12.5 & & & \\
\hline Male & & & & \\
\hline Female (Ref) & 39.4 & 1.081 & $0.994-1.177$ & 0.070 \\
\hline $\begin{array}{l}\text { Mother's Educational } \\
\text { Level }\end{array}$ & 37.8 & & & \\
\hline No Education & & & & \\
\hline Primary & 51.3 & 1.016 & $0.853-1.211$ & 0.857 \\
\hline Secondary & 42.4 & $0.932(-)$ & $0.777-1.118$ & 0.448 \\
\hline Higher & 27.5 & $0.705(-)$ & $0.593-0.838$ & 0.000 \\
\hline No Education (Ref) & 12.4 & $0.420(-)$ & $0.319-0.553$ & 0.000 \\
\hline Age & 44.6 & & & \\
\hline $6-18$ months & & 1.018 & $0.994-1.177$ & 0.000 \\
\hline $19-32$ months & 29.6 & & & \\
\hline $33-46$ months & 38.1 & & & \\
\hline $47-59$ months & 42.3 & & & \\
\hline Location of Source of & 45.2 & & & \\
\hline $\begin{array}{l}\text { Water } \\
\text { In Own dwelling }\end{array}$ & & & & \\
\hline In own yard & 30.2 & $0.942(-)$ & $0.806-1.101$ & 0.450 \\
\hline Elsewhere (Ref) & 36.0 & $0.997(-)$ & $0.886-1.122$ & 0.961 \\
\hline Number of Children & 40.4 & & & \\
\hline Less than 5 & & & & \\
\hline 5 and above & & 1.100 & $1.057-1.144$ & 0.000 \\
\hline Genotype & 38.1 & & & \\
\hline AA & 50.5 & & & \\
\hline AS & & & & \\
\hline $\mathrm{AC}$ & 40.5 & 1.631 & $0.366-7.268$ & 0.521 \\
\hline $\mathrm{SC}$ & 32.3 & 1.546 & $0.346-6.906$ & 0.568 \\
\hline SS & 13.1 & 2.393 & $0.515-11.117$ & 0.266 \\
\hline Other (Ref) & 3.0 & 1.867 & $0.351-9.921$ & 0.464 \\
\hline & 60.2 & $0.775(-)$ & $0.161-3.724$ & 0.751 \\
\hline
\end{tabular}

\section{DISCUSSION}

Descriptive analysis showed that malaria prevalence in children is highest in the North West region (52.3\%) while the South East has the least prevalence of $28.1 \%$. Malaria in children was more prevalent in the urban centers $(74.4 \%)$ than the rural areas $(46.5 \%)$. Prevalence is higher in places with higher altitude of more than 500 meters above sea level (40.8\%) than in places below 500 meters above sea level (38.3\%). Lower malaria prevalence in children was observed in families with higher wealth 
index. In other words, malaria prevalence decreases with increase in wealth index (table 3). Gender significantly affects the malaria prevalence as males are $39.4 \%$ compared to females $(37.8 \%)$. Mother's level of education was significant. Prevalence decreases with increase in the mother's level of education. Children in the 6 -18 months age range had lower malaria prevalence than the older children. In other words, prevalence increases with increase in age. Also malaria prevalence increases with increase in the number of children. Lower prevalence was observed in households where all children sleep under bed nets. SS genotype had the highest prevalence while lowest prevalence was observed in SC genotype. Binary logistic regression analysis was carried out to assess the effect of the observed risk factors on the malaria prevalence in children $6-59$ months old. The results showed malaria positivity in children $(6-59$ month) was significantly associated with the regional location $(\mathrm{p}<0.001)$. Compared with the reference region (South West), North West region had $0.690,95 \% \mathrm{CI}=0.574-$ 0.829 , North Central $0.570,95 \%$ CI $=0.484-0.672$, North East had 0.348 times higher odds of malaria positivity $95 \% \mathrm{CI}=0.290$ - 0.417 while South East and South South have lower odds with 0.527 and 0.436 respectively. Odds of malaria positivity decreases in the urban centers compared to rural areas. Malaria positivity is equally likely with regards to the cluster altitude $(\mathrm{OR}=1.000$, $95 \% \mathrm{CI}=0.999-1.000)$. All children sleeping under bed net reduces the risk of malaria positivity by $3 \%$. Children not sleeping under mosquito bed net increases odds of malaria positivity (OR $=1.132,95 \% \mathrm{CI}=0.985-1.302$ ).

The results showed a very significant effect of wealth index on malaria positivity. The poorest had 6.6 times higher odds of malaria positivity compared to the reference group (richest). Poorer had 5.4 higher, middle had 3.7 higher and richer had 2.6 times higher. Male had approximately 1.1 higher odds of malaria positivity than female. Children of mothers without education had 1.0 higher odds of malaria positivity while the chance of malaria positivity of children of mothers with higher education decreases by $58 \%$. A one month age increase raises the odd of malaria positivity by 1.018. Significance of the difference in the location of source of water was not observed. Significant effect was observed in the difference in the number of children. Increase in the number of children affects the increase in the odds of malaria positivity by 1.1 . Being in the SS genotype group reduces the odds of malaria positivity by $22 \%$.

\section{CONCLUSION}

According to Nigeria Demographic and Health Survey 2018, the malaria RDT prevalence in children (aged 6 - 59 months) stands at 38.6\%. In relative terms, North West region had the highest malaria prevalence $(11.9 \%)$ while South South had the least prevalence $(3.1 \%)$. Malaria was significantly prevalent in all the six regions. All the eleven risk factors used in this analysis were significantly associated with malaria prevalence in children (aged 6-59 months) except location of the source of water and genotype. In other words, the identified risk factors have significant effects on malaria positivity in children aged $6-59$ months. For instance, the chance of malaria positivity increases with lower level of mother's of education.

\section{REFERENCES}

[1] Abossie, A., Yohanes, T., Nedu, A., Tafesse, W., Damitie, M. (2020) Prevalence of Malaria and Associated Risk Factors Among Febrile Children Under Five Years: A Cross-Sectional Study in Arba Minch Zuria District, South Ethiopia. Infection and Drug Resistance 13:363-372

[2] Adam, I., Khamis, A. H., Elbashir, M. I.(2005) Prevalence and Risk Factors for Plasmodium Falciparum Malaria in Pregnant Women of Eastern Sudan. Malaria Journal 4(18).

[3] Ajakaye, O. G, Ibikunoluwa M. R. (2020) Prevalence and Risk of Malaria, Anemia and Malnutrition Among Children in IDPs Camp in Edo State, Nigeria. Parasite Epidemiology and Control 8: 2405-6731

[4] Ayano, B, Amentie, B. (2018) Assessment of Prevalence and Risk Factors for Anemia Among Pregnant Mothers Attending Anc Clinic at Adama Hospital Medical Collage, Adama, Ethiopia. Journal of Gynecology and Obstetrics 6(3): 31-39

[5] Ayele, D. G., Zewotir, T. T., Mwambi, H. G. (2012) Prevalence and Risk Factors of Malaria in Ethiopia. Malaria Journal 11:195

[6] Bah, M. S. (2020) "The Relationship Between Malaria Status in Under-five Children and Some Household Demographic, Socioeconomic and Environmental Factors Associated with the Disease in Sierra Leone." Thesis, Georgia State University. https://scholarworks.gsu.edu/iph_theses/706

[7] Cahyaningrum, P., Sulistyawati, S. (2018) Malaria Risk Factors in Kaligesing, Purworejo District, Central Java Province, Indonesia: A Casecontrol Study. Journal of Preventive Medicine \& Public Health 51:148153

[8] Chaponda, E. B., (2017) The Epidemiology of Malaria, Curable Sexually Transmitted and Reproductive Tract Infections and their Co-infection Among Pregnant Women in a Catchment Area in Nchelenge District, Zambia. PhD thesis, London School of Hygiene \& Tropical Medicine. http://researchonline.lshtm.ac.uk/id/eprint/4398420/

[9] Clark, T. D., Greenhouse, B., Meya, D. N., Nzarubara, B. Sebuguzi, C. M., Staedke, S. $\quad$ G., Seto, E., Kamya, M. R., Rosenthal, P. J., Dorsey, G. (2008) Factors Determining the Heterogeneity of Malaria Incidence in Children in Kampala, Uganda. The Journal of Infectious Diseases 198:393-400

[10] Dawaki, S. Hesham, M. A, Ithoi I, Ibrahim, J. Atroosh, W. M. Abdulsalam, A. M. Sady, H. Elyana, F. N. Adamu, A. U. Yelwa, S. I. Ahmed, A. AlAreeqi, M. A. Subramaniam, L. R. Nasr, N. A. Lau, Y. (2016) Is Nigeria Winning the Battle Against Malaria? Prevalence, Risk Factors and KAP Assessment Among Hausa Communities in Kano State Malaria Journal 15( 351).

[11] Ernst, K. C., Lindblade, K. A., Koech, D., Sumba, P. O., Kuwuor, D. O., John, C. C., Wilson, M. L. (2009) Environmental, Socio-demographic and Behavioural Determinants of Malaria Risk in the Western Kenyan Highlands: A Case-control Study. Tropical Medicine and International Health 14(10): 1258-1265

[12] Eunice, A., Warijoya, A. Luboobi, L. (2017) Statistical Modelling of Malaria Incidences in Apac District Uganda. Open Journal of Statistics 7 901- 919.

[13] Fekadu, M. Yenit, M. K. Lakew, A. M. (2018) The Prevalence of Asymptomic Malaria Parasitemia and Associated Factors Among Adults in Dembia District, Northwest Ethiopia. Archives of Public Health 76(74)

[14] Gahutu, J. B., Steininger, C., Shyirambere, C., Zeile, I., Cwinya-Ay, N., Danquah, I., Larsen, C. H., Eggelte, T. A., Uwimana, A., Karema, C., Musemakweri, A., Harms, G., Mockenhaupt, F. P. (2011) Prevalence and risk factors of malaria among children in southern highland Rwanda. Malaria Journal 10(134)

[15] Hasyim, H. Dale, P. Groneberg, D. A. Kuch, U. Muller, R. (2019) Social Determinants of Malaria in an Endemic Area of Indonesia. Malaria Journal 18(134).

[16] Herrera, S., Ivanovich, E., Ye, Y., Garley, A. (2020) Surveillance, Monitoring and Evaluation of Malaria Programs: Online Course. Chapel Hill, NC, USA: Measure Evaluation, University of North Carolina. 2-7

[17] Homan, T., Maire, N., Hiscox, A., Pasquale, A. D., Kiche, I., Onoka, K., Mweresa, C., Mukabana5, W.R., Ross, A ., Smitha, A. T., Takken, W. (2016) Spatially Variable Risk Factors for Malaria in a Geographically Heterogeneous Landscape, Western Kenya: An Explorative Study Malaria Journal 15(1)

[18] Kanyangarara, M, Mamini, E, Mharakurwa, S, Munyati, S, Gwanzura, L, Kobayashi, T, Shields, T, Mullany, LC, Mutambu, S, Mason, PR, Curriero, FC, Moss, WJ. (2016) Individual and Househol Level Risk Factors 
Associated with Malaria in Mutasa District, Zimbabwe: A Serial CrossSectional Study. American Journal of Tropical Medicine and Hygiene 95(1) $133-140$

[19] Konradsen, F, Amerasinghe, P, Hoek, WVD, Amerasinghe, F, Perera, D, Piyaratne, M. (2003) Strong Association Between House Characteristics and Malaria Vectors in Sri Lanka. American Journal of Tropical Medicine and Hygiene 68(2) 177-181

[20] Morakinyo, O. M., Balogun, F. M. Fagbamigbe, A. F. (2018) Housing Type and Risk of Malaria Among Under-five Children in Nigeria: Evidence from the Malaria Indicator Survey. Malaria Journal 17(311).

[21] Mosha, J. F., Lukole, E., Charlwood, J. D., Wright, A., Rowland, M., Bullock, O., Manjurano, A., Kisinza, W., Mosha, F. W., Kleinschmidt, I., Protopopoff, N. (2020) Risk Factors for Malaria Infection Prevalence and Household Vector Density Between Mass Distribution Campaigns of Long-Lasting Insecticidal Nets in North-western Tanzania. Malaria Journal 19:297

[22] Mwalimu, C. D., Mghamba, J., Mohamed, A., Hussein, Abade, A., Mubi, M. (2020) Factors Associated With Persistent Malaria Transmission in Urban Peripheral Areas Dar es Salaam Region, Tanzania. Journal of Public Health International 3(1): 28-44

[23] Nigeria Malaria Fact Sheet (2016)

[24] http://photos.state.gov/libraries/nigeria/231771/Public/DecemberMalariaFactSheet2.pdf Accessed 17-03-2020 9:30 AM

[25] Philips, A, Bassett, P, Zeki, S, Newman, S, Pasvol, G. (2009) Risk Factors for Severe Disease in Adults with Falciparum Malaria. Clinical Infectious Diseases 48 871-878.

[26] Pullan, R. L., Bukirwa, H., Staedke, S. G., Snow, R. W., Brooker, S. (2010) Plasmodium Infection and its Risk Factors In Eastern Uganda. Malaria Journal 9(2)

[27] Putri, M. M., Ishak, H.. Indar, A. M. (2020) Analysis of Environmental Risk Factors and Treatment Efforts Malaria Import Patients in Puskesmas in the Work Area of District Health Center of Segeri, Pangkep Regency. Medicolegal Update 20(3) 757-762

[28] Ramdzan, A. R., Ismail, A., Mohd Zanib, Z. S. (2020) Prevalence of Malaria and its Risk Factors in Sabah, Malaysia. International Journal of Infectious Diseases 91: 68-72

[29] Samadoulougou, S. Maheu-Giroux, M. Samadoulougou, F. K. Keukeleire, M. D. Castro, M. C. Robert, A. (2014) Multilevel and Geo-Statistical Modeling of Malaria Risk in Children of Burkina Faso. Parasites and Vectors 7(1) 350 .

[30] Severe Malaria Observation http://www.severemalaria.org/countries/nigeria

[31] Seyoum, S. (2018) Analysis of Prevalence of Malaria and Anemia Using Bivariate Probit Model. Annals of Data Science 5(2):301-312

[32] Sintasath, D. M., Ghebremeskel, T., Lynch, M., Kleinau, E., Bretas, G., Shililu, J., Brantly, E., Graves, P. M., Beier, J. C. (2005) Malaria Prevalence and Associated Risk Factors in Eritrea. American Journal of Tropical Medicine and Hygiene 72(6) 682-687

[33] Siri, J. G., (2014) Independent Associations of Maternal Education and Household Wealth with Malaria Risk in Children. Ecology and Society 19(1) 33-52

[34] Sluydts, V., Heng, S., Coosemans, M., Roey, K. V., Gryseels, C., Canier, L. Kim, S., Khim, N., Siv, S., Mean, V., Sambunny, U., Grietens, K. P., Tho, S., Menard, D., Durnez, L. (2014) Spatial Clustering and Risk Factors of Malaria Infections in Ratanakiri Province, Cambodia. Malaria Journal $13: 387$

[35] Tesfay, K. Yohannes, M. Mardu, F. Berhe, B. Negash, H. (2019) Assessment of Community Knowledge, Practice, and Determinants of Malaria Case Households in the Rural Area of Raya Azebo District, Northern Ethiopia, 2017. PLoS ONE 14(10)

[36] Tesfahunegn, A Berhe, G Gebregziabher, E. (2019) Risk Factors Associated With Malaria Outbreak in Laelay Adyabo District Northern Ethiopia: CaseControl Study Design BMC Public Health 19(484)

[37] USAID (2019) President's Malaria Initiative, Nigeria Malaria Operational Plan FY 2019.

[38] Weisberg, S. (2005) Applied Linear Regression (Third Ed.). John Wiley \& Sons, Inc., Hoboken, New Jersey.251-266

[39] Whiteman, A., Mejia, A., Hernandez, I., Loaiza, J. R. (2018) Socioeconomic and Demographic Predictors of Resident Knowledge, Attitude, and Practice Regarding Arthropod-borne Viruses in Panama. BMC Public Health 18 (1261).

[40] Xiang, J., Hansen, A., Liu, Q., Tong, M. X., Liu, X., Sun, Y., Cameron, S., Hanson- Easey, S., Han, G. S., Williams, C., Weinstein, P., Bi, P. (2018) Association Between Malaria Incidence and Meteorological Factors: a Multi-Location Study in China, 2005-2012. Epidemiology and Infection 146: 89-99

[41] Yadav, K., Dhiman, S., Rabha, B., Saikia, P. K., Veer, V. (2014) Socioeconomic Determinants for Malaria Transmission Risk in an Endemic Primary Health Centre in Assam, India. Infectious Diseases of Poverty 3(19)

\section{AUTHORS}

First Author - Garba Sahabi Adamu, Department of Mathematics, Waziri Umaru Federal Polytechnic, Birnin Kebbi, Nigeria

Second Author - Gerald Onwuka, Department of Mathematics and Statistics, Kebbi State University of Science and Technology Aliero, Kebbi State Nigeria 